\title{
Impacts of Electric Vehicle Charging under Cold Weather on Power Networks
}

\author{
I Safak Bayram \\ Department of Electronic and Electrical Engineering \\ University of Strathclyde \\ Glasgow, United Kingdom \\ safak.bayram@strath.ac.uk
}

\begin{abstract}
Deep decarbonisation of the transportation requires widespread adoption of electric vehicles (EVs). Currently, the dominant energy storage technology for EVs is lithium based batteries which are designed to work under mild ambient temperatures (e.g. 21 Celsius). However, most cities with high EV penetration experience cold winter months when the performance of EVs is significantly degraded. In this paper, we present an impact assessment of cold weather EV charging on the power networks by reviewing existing literature on empirical studies related to battery performance, $\mathrm{EV}$ driving range, and charger characteristics. Two potential issues are identified. First, charging EVs at low temperatures significantly increases distribution network harmonics, hence limits the number of EVs that can be charged at the same time. Second, more frequent charging of EVs increases demand from the grid. To quantify this, a Monte Carlo based simulation is developed for the case of UK and results show that nearly $450 \mathrm{MW}$ of extra generation is needed to cushion impacts of cold weather charging of 11 million vehicles. The problems pertinent to temperature effects on $\mathrm{EV}$ charging require greater attention as EVs are becoming the main mode of transport in the next decade.
\end{abstract}

Index Terms-Electric Vehicles; Power Grid Impact; Battery Degradation;Cold Weather Charging

\section{INTRODUCTION}

Electric vehicles (EVs) are considered as key technologies to decarbonise the transport sector, which represents more than one third of the global greenhouse gas emissions [1]. $\mathrm{EV}$ adoption is further supported by national commitments shaped by the Paris Agreement (signed in 2015) to achieve net-zero emissions by 2050. Several governments including the UK, France, and Denmark have introduced bolder policies and ban the sale of new gas-powered vehicles to accelerate EV adoption rates [2], [3]. To that end, it is expected that $30 \%$ of all passenger vehicles worldwide will be EVs by 2032, while more than 10 million EVs are forecasted to be on the road in the UK by 2030 [4].

Transportation electrification is a multifaceted transformation that impacts drivers, power grid operators, and the way transportation networks are designed. Particularly for the power network operators, increasing shares of renewables introduces higher levels of uncertainties at the power generation side and new stability and reliability issues arise due to reduced system inertia [5]. It is projected by the National Grid, transmission operator in the UK, that $£ 30$ billion of
TABLE I

Average Monthly Temperatures $\left(\right.$ IN $\left.{ }^{\circ} \mathrm{C}\right)$ For Selected Cities With High Electric Vehicle Penetration [?]

\begin{tabular}{llccc}
\hline City & Country & December & January & February \\
\hline Bejing & China & -0.9 & -3.1 & 0.3 \\
Seoul & South Korea & 0.4 & -2.4 & 0.4 \\
Oslo & Norway & -3.1 & -4.3 & -4 \\
Helsinki & Finland & -2 & -3.9 & -4.7 \\
Stockholm & Sweden & -1 & -2.8 & -3 \\
Vienna & Austria & 1.1 & 0.3 & 1.5 \\
Berlin & Germany & 1.3 & 0.6 & 2.3 \\
Amsterdam & Netherlands & 4 & 3.4 & 3.5 \\
Edinburgh & United Kingdom & 4.2 & 4.3 & 4.5 \\
Montreal & Canada & -5.4 & -9.7 & 7.7 \\
Chicago & USA & -2.4 & -4.6 & -2.4 \\
New York & USA & 3.3 & 0.6 & 2.1 \\
\hline
\end{tabular}

investments are needed by 2030 to host EVs in the UK [6] for grid reinforcements.

Furthermore, a number of studies present how uncontrolled EV charging could negatively impact the power grid. At the distribution network, EV charging accelerates transformer ageing [7], impacts power quality (voltage dips, unbalances, harmonics etc.) [?], [8], and trigger supply shortages [9]. EV demand is likely to increase the overall peak demand. In California, the additional EV demand is projected to increase the peak demand by $25 \%$ [10]. In [11], electricity demand of large collections of EVs in Germany is studied. It is concluded that EV charging could increase the peak demand by $20 \%$ by 2050. For the case of UK, it is estimated that $19 \mathrm{TWh}$ of energy would be needed by 2035 if $30 \%$ of the car fleet is electrified [12].

On the other hand, the majority of the existing feasibility and risk assessment studies assume that EVs operate at optimum driving conditions $\left(21.5^{\circ} \mathrm{C}\right)$ when the underlying lithium ion battery technology uses the least amount of power for cruise $(\mathrm{kWh} / \mathrm{mile})$. However, the ambient temperatures in most cities with the highest amount of EV penetrations are typically low due to long and cold winter months. Table I presents the average daily temperatures in winter months for selected cities in the northern hemisphere. It can be seen that ambient temperatures are significantly lower than optimal temperatures

More specifically, the operation of EV charging infrastruc- 
TABLE II

BATTERY CAPACITY AND CHARGING RATES FOR TOP 10 EV MODELS IN THE UK.

\begin{tabular}{lcc}
\hline Vehicle Model & $\begin{array}{c}\text { Battery } \\
(\mathrm{kWh})\end{array}$ & $\begin{array}{c}\text { Available Charging } \\
\text { Power }(\mathrm{kW})\end{array}$ \\
\hline Nissan Leaf & 40 & $2.3-40$ \\
Tesla Model 3 Std Range+ & 50 & $2.3-65$ \\
Tesla Model 3 LR Dual Motor & 75 & $2.3-85$ \\
BMW i3s 120 Ah & 42.4 & $2.3-47$ \\
Renault Zoe ZE50 & 54.7 & $2.3-41$ \\
Tesla Model S Perf. & 100 & $2.3-125$ \\
Tesla Model S LR+ & 100 & $2.3-125$ \\
Volkswagen e-Golf & 35.8 & $2.3-39$ \\
Jaguar I-Pace EV400 & 90 & $2.3-85$ \\
Volvo XC40 P8 & 75 & $2.3-100$ \\
\hline
\end{tabular}

tures and the EV batteries are negatively impacted under cold weather because:

- EV driving ranges reduce significantly due to the additional need for battery/cabin heating and to provide the extra traction needed to drive [13], [14];

- when the battery is cold, battery management system (BMS) of an EV significantly limits the charging rate of DC fast chargers [15] which introduces additional harmonics at the distribution network;

- the utilisation of public chargers will be higher and EV load profiles could shift to peak hours during winter; and

- there will be an additional baseline energy demand to keep parked EVs warm.

It is noteworthy that the hot weather has a similar impact as EVs need to cool the battery to optimal temperatures and drivers use air conditioning to cool the batteries. However, only cold weather impacts are considered since the EV penetration is relatively low in regions located in desert climates. In this paper, we present an overview of the studies that investigate the impacts of cold weather on power networks and present a case study on how EV charging increases power generation.

\section{VEHICLE LEVEL IMPACTS}

\section{A. EV Battery}

Over the last couple of years, a number of empirical studies were conducted to understand the impacts of cold weather on driving rages. In Ref. [13], a simulation-based study is presented to examine the impacts of cabin heating in cold weather $\left(0{ }^{\circ} \mathrm{C}\right)$. It is shown that the all electric range could reduce by $40 \%$ when the cabin temperature is set to $20{ }^{\circ} \mathrm{C}$. In a more accurate study presented in [14], measurements were taken from two popular EV models which were driven in Winnipeg, Canada. It was shown that driving distance of Nissan Leaf could drop from $162 \mathrm{~km}$ in $28{ }^{\circ} \mathrm{C}$ to $44 \mathrm{~km}$ in $-26{ }^{\circ} \mathrm{C}$.

In [16], a literature review on the impacts of low temperatures on EV batteries is presented. The authors focused on nine major effects namely, capacity losses, life degradation (ageing), power losses, safety, thermal management system issues, battery model and state estimations, incremental cost, charging

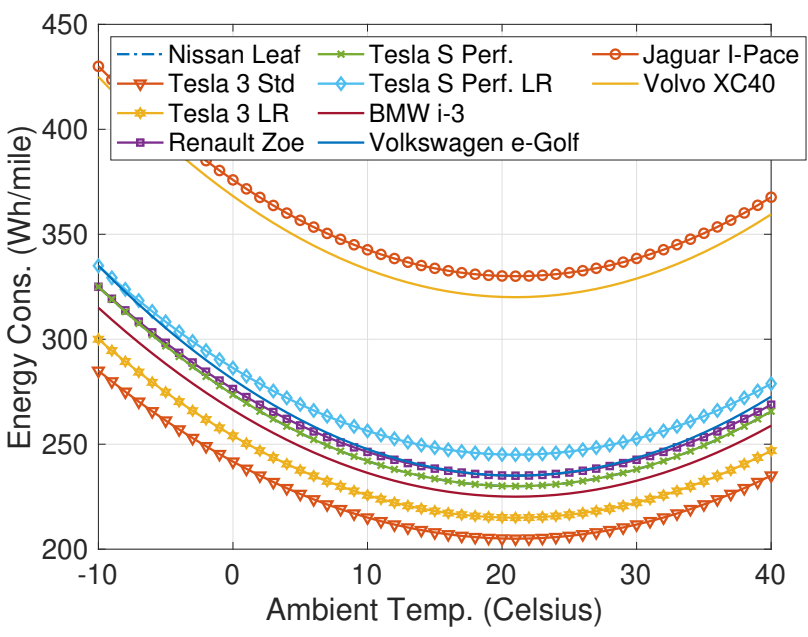

Fig. 1. EV Driving ranges of selected models with respect to varying ambient temperatures [18]

difficulty, and unbalanced capacity. The role of managing and controlling the battery temperature is further discussed in detailed. The variations in cell-to-cell temperatures need to be minimised to avoid battery system underperformance. Over the next decade, the battery technology is expected to advance significantly due to novel materials science technology. One such potential candidate is Lithium iron phosphate (LFP) which promises faster charging compared to existing batteries and performs better under extreme weather conditions [17]. However, LFP is more desirable for EVs requiring lower battery pack (e.g. $40 \mathrm{kWh}$ ) as it shows weaker performance on range. LFP further offers improvements on depth of discharge (DoD) levels. For instance, EVs can be charged for wider DoD ranges than existing 20\%-80\% range. Another direction in the battery technology is solid state batteries (SSB) which are considered as the "holy grail" of the battery technology due to their potential for safety and high energy. SSB is envisioned to be used in luxury and sports cars due to high technology cost.

In Table II, top selling EV models, their battery packs, and available charging powers are presented. Furthermore, in Figure 1, driving ranges of popular (top selling in the UK) EV models are presented. The figure is adopted from [18] which presents data collected from $4200 \mathrm{EVs}$ and 5.2 million trips in various parts of the United States. It can be seen that most vehicle models' driving range reduce by more than one third at $-10^{\circ} \mathrm{C}$ when compared to optimal driving temperature of $21.5^{\circ} \mathrm{C}$. It is important to note that the values presented in Figure 1 are averaged over all vehicles of the same type and actual energy consumption depends on three main factors [19]: (i) energy used for vehicle propulsion (speed, acceleration, etc.), (ii) energy consumed by auxiliaries (heating, electronics, etc.) and (iii) regenerative energy during deceleration. In [19], energy consumption level of 55 electric taxis in China are analysed, and it was shown that ambient temperature plays a leading role in battery depletion. 
TABLE III

TWO YEAR LONG EV CHARGING STATISTICS COLLECTED FROM NORWAY [20].

\begin{tabular}{cccc}
\hline County & $\begin{array}{c}\text { Average } \\
\text { Energy (kWh) }\end{array}$ & $\begin{array}{c}\text { Average } \\
\text { Duration }(\mathrm{min})\end{array}$ & $\begin{array}{c}\text { Average } \\
\text { Power }(\mathrm{kW})\end{array}$ \\
\hline Akershus & 9.2 & 20 & 29.9 \\
Buskerud & 10.1 & 20 & 32.2 \\
Hedmark & 11.2 & 21.5 & 30.7 \\
Oslo & 9.4 & 20.8 & 29.4 \\
Vest-Agder & 8.9 & 19.7 & 29.6 \\
Telemark & 10.5 & 20.7 & 32.2 \\
Norway & 9.6 & 20.5 & 30.2 \\
\hline
\end{tabular}

\section{B. Charger Testing}

1) Fast Charging: Cold temperatures further reduce the charging rate of EV batteries as the battery management system limits current flow to avoid detrimental effects on the battery cells [14]. In [15], authors conducted a statistical analysis to examine the relationship between fast DC charging rate and the cold temperature using two $50 \mathrm{~kW}$ DC fast chargers used to charge Nissan Leaf EVs that were used as taxis in New York. It was shown that the time to reach $80 \%$ SoC under $25^{\circ} \mathrm{C}$ is around $20-25$ minutes, while this duration extends to 55-60 minutes when the ambient temperature is around $0^{\circ} \mathrm{C}$. In [21], authors evaluated fast charger efficiency under extreme temperatures. The results show that the efficiency of most commercial chargers reduces to $80-90 \%$ under $-15{ }^{\circ} \mathrm{C}$ and to $40-50 \%$ under- $25{ }^{\circ} \mathrm{C}$. In [15], authors further present statistical models to estimate the charging durations for a given ambient temperatures. Using regression analysis, the following function is devised to represent the final state of charge level $S$, for a given charging duration $t$ (in minutes), ambient temperature $T$ (in celsius), and initial state of charge level $S_{0}$ :

$$
S(t)=\left(S_{0}+\frac{\beta_{0}+\beta_{1} T}{\beta_{2}}\right) e^{\beta_{2} t}-\frac{\beta_{0}+\beta_{1} T}{\beta_{2}},
$$

where $\beta_{0}, \beta_{1}$, and $\beta_{2}$ are parameters and calculated as 0.015 , 0.00034 , and -0.022 , respectively. Function given above is evaluated for a five different temperatures and charging duration (shown in Figure 2). It can be seen that at lower temperatures, the charging power significantly reduces. For instance, to reach $50 \% \mathrm{SoC}$, it takes about 21 minutes at $20^{\circ} \mathrm{C}$, while this duration is nearly 60 minutes at $-5^{\circ} \mathrm{C}$. Recharging times are particularly important for EV fleets such as taxis, delivery vehicles or buses as they need to follow a certain schedule.

2) Level 2 Charging: The impacts of cold weather EV charging were empirically examined by Idaho National Labs through charging of a Nissan Leaf with a level 2 charger [22]. As shown in Figure 3, the charger draws constant power of $6.6 \mathrm{~kW}$ until the last one one and half hours and then monotonically decreases until the end of the charging session. It can be observed that the cold weather does not significantly impact the charging pattern because the charging power is relatively low compared to fast charging case and does not

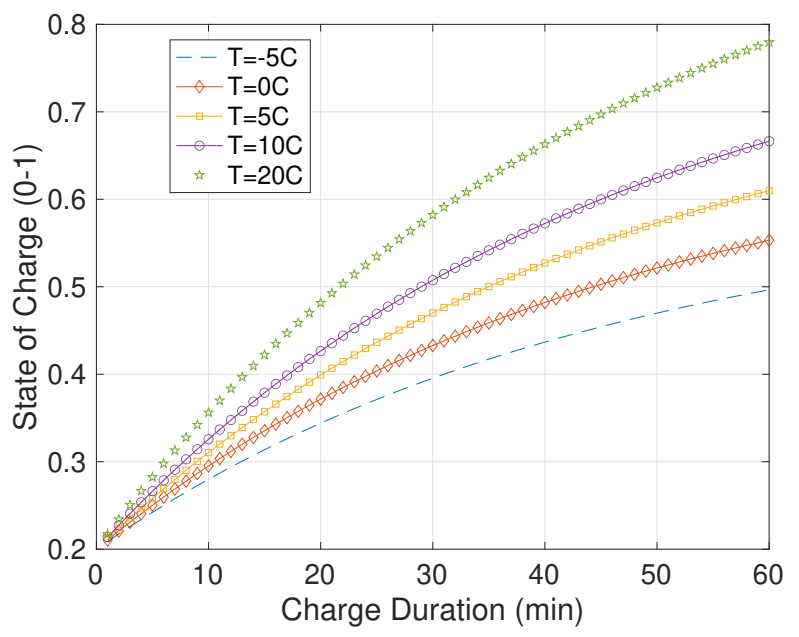

Fig. 2. Nissan Leaf charging durations under different ambient temperatures.

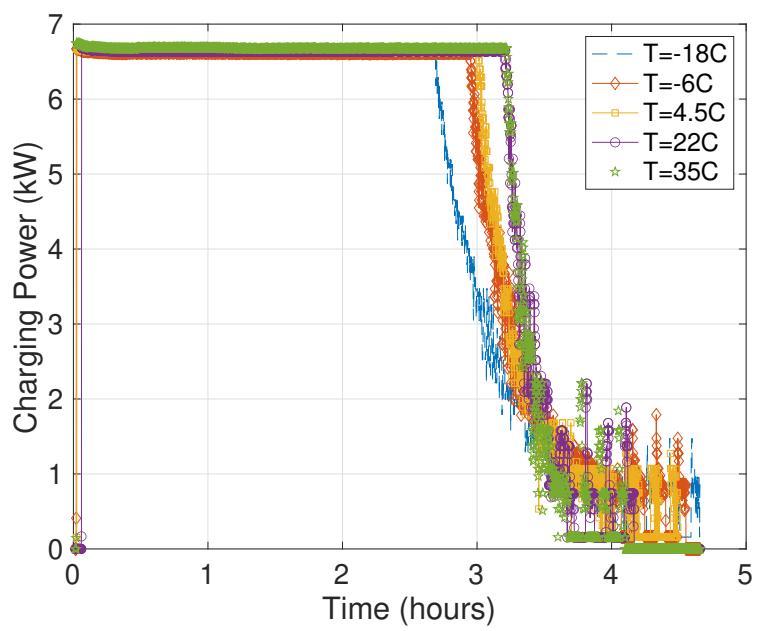

Fig. 3. Level 2 charging under different temperatures (Data: [23]).

impact the battery. To that end, the cold weather primarily impacts the fast charging patterns.

A more comprehensive study is conducted in Norway which focuses on the impacts of cold weather for EV charging [20]. The dataset contains almost two years (Q1 2016 - Q1 2018) of EV charging collected 1500 Chademo standard fast chargers $(60 \mathrm{~kW}$ located in more than 500 different from stations. As shown in Table III, average charging rates are significantly lower than the rated capacity $(50 \mathrm{~kW})$. Moreover, since the table represents year long averages, charger rates in winter months is expected to be lower than the ones presented in the table.

\section{POWER NETWORK IMPaCtS}

\section{A. Distribution Network}

As given in the introduction, the impacts of EV charging has been throughly investigated in the literature. However, there is very limited work on the impact assessment by further considering the cold weather charging that were described 


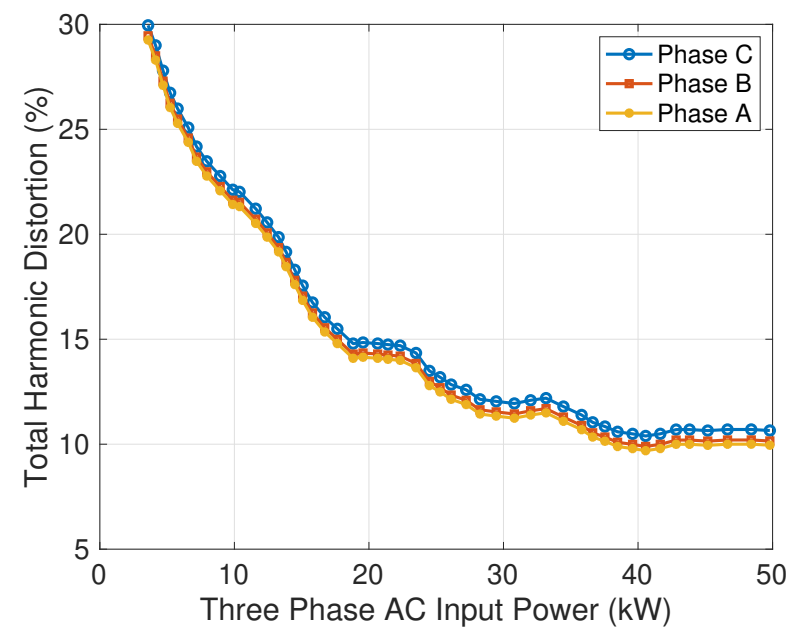

Fig. 4. DC Fast charger input current harmonic distortion performance (ABB Tera 53 CJ) (Data: [23]).

in the previous section. By investigation, the cold weather greatly impacts the charging rate of fast chargers. In [23], experiments were carried out using ABB Tera 53 CJ $50 \mathrm{~kW}$ fast chargers by varying the rated power. As shown in Figure 4 , when the charger output reduces, the charger introduces additional harmonics to the network.

The harmonic distortion is a major power quality concern that requires particular attention. In the United Kingdom, EVs that are charged with a connection that is less than 16 A are required to follow IEC 61000-3-2 regulations [24] and compliance with this standard enables unconditional connection to distribution grid. On the other hand, 50kW DC fast chargers typically use 75 Amps (maximum RMS) per phase (see [23]), hence, connection of such equipments to the distribution network is subject to IEC61000-3-12, however, different from slow charger case compliance with IEC610003-12 does not guarantee unconditional network connection. The primary reason behind this is that the connection location (e.g. distance from the substation) of the charger also impacts the power quality. Therefore, the number and the location of fast chargers needs to be carefully considered to avoid increased network chargers needed for widespread reactive reinforcement schemes.

By considering the harmonic current distortion of $\mathrm{EV}$ chargers, particularly in winter, it is critical to determine the maximum number of EVs that be hosted at a specific point of common coupling (PCC). By examining the harmonic distortion, it can be seen that the number of EVs that can be charged at the same time in winter is likely to be less than the concurrent charging in summer. Therefore, the maximum number of EVs that be charged at the same time is a range rather than a specific value. To carry out a more holistic assessment, probabilistic methods could be developed to capture randomness of events that are related to EV arrivals, departures, and the existing load on the network. In [25], a

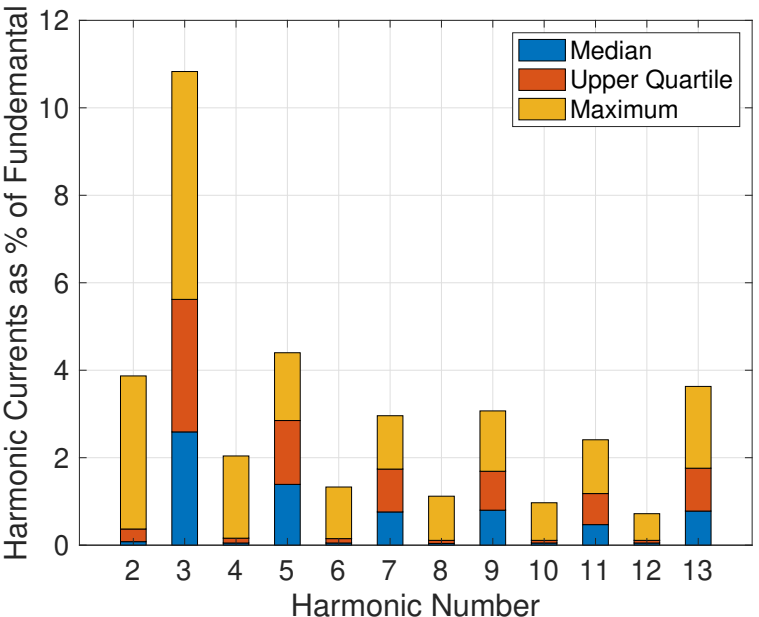

Fig. 5. Harmonic current measurement as percentage of Fundamental Current for chargers draw less than 16 amps. Median, upper quartile, and maximum harmonics levels are presented. (Data: [25]).

TABLE IV

NUMBER OF EVS THAT CAN BE CHARGED AT THE SAME TIME UNDER VARIOUS SCENARIOS IN WESTERN POWER NETWORK (WPD) [25].

\begin{tabular}{llllll}
\hline & & \multicolumn{4}{c}{ Number of EVs } \\
\hline \multirow{2}{*}{$\begin{array}{c}\text { Background } \\
\text { Harmonics }\end{array}$} & Harmonics Level & Charger Type & $10 \%$ & $20 \%$ & $30 \%$ \\
\hline WPD & Median & $3.6 \mathrm{~kW}$ & 17 & 19 & 21 \\
WPD & Median & $7.2 \mathrm{~kW}$ & 17 & 19 & 21 \\
WPD & Upper Quartile & $3.6 \mathrm{~kW}$ & 14 & 15 & 15 \\
WPD & Upper Quartile & $7.2 \mathrm{~kW}$ & 3 & 4 & 4 \\
None & Median & $3.6 \mathrm{~kW}$ & 17 & 20 & 22 \\
None & Median & $7.2 \mathrm{~kW}$ & 18 & 22 & 23 \\
None & Upper Quartile & $3.6 \mathrm{~kW}$ & 13 & 15 & 16 \\
None & Upper Quartile & $7.2 \mathrm{~kW}$ & 3 & 4 & 4 \\
\hline
\end{tabular}

probabilistic methodology is developed to assess the number of EVs that can be charged in Western Power Distribution (WPD) company's network. As an initial step, 23 individual EVs were charged using $3.6 \mathrm{~kW}$ and $7.2 \mathrm{~kW}$ chargers and their harmonics performance was measured (depicted in Figure 5).

Next, maximum number of EVs that can be concurrently charged is determined with respect to the probability of failure using pass or fail against IEC 61000-3-2 standard. Total of eight scenarios were created using the combinations of existing background harmonics (existing harmonics in the WPD network and zero background harmonics), vehicle harmonic level (median and upper quartile as in Figure 5), and two charge levels $(3.6 \mathrm{~kW}$ and $7.2 \mathrm{~kW})$. The results presented are presented in Table IV. For instance, when there is $0 \%$ background harmonics and EVs are charged with a $7.2 \mathrm{~kW}$ chargers, then 18 EVs can be charged simultaneously with a $10 \%$ probability of failure. The results further show that existing harmonics level and the EV harmonics level significantly impact the number of EVs that be charged at the same time. Moreover, as the probability of failure condition is relaxed, higher number of EVs can be hosted in a given 
TABLE V

PERCENTAGE OF CAR DRIVER TRIPS BASED ON DISTANCE DRIVEN IN THE UK [26].

\begin{tabular}{llllllllll}
\hline $\begin{array}{c}\text { Distance per } \\
\text { trip (miles) }\end{array}$ & $<1$ & $1-2$ & $2-5$ & $5-10$ & $10-25$ & $25-50$ & $50-100$ & $>100$ \\
\hline \% of trips & 6.45 & 16.99 & 32.94 & 21.02 & 16.24 & 4.25 & 1.42 & 0.68 \\
\hline
\end{tabular}

feeder.

\section{B. Power Generation}

The cold weather charging of EVs on power generation can be probabilistically quantified by developing Monte Carlo simulations to estimate the amount of EVs that require extra charge during the same day due to energy consumed for heating the battery and the cabin. This section presents one such study for the case of UK and 11 million EVs is assumed to be on the roads by 2030. The Monte Carlo simulation is based on statistical sampling of various system parameters that determine the aggregate EV load profile. The most important simulation parameters are number of EVs, battery packs, driving patterns, charger types, ambient temperature, length and frequency of trips, initial and final battery state of charge levels. System parameters, their types, data sources are presented in Table VI.

For instance, data archives from Centre for Environmental Data Analysis (CEDA) [28] are used to obtain hourly temperatures (averaged over the last three years (2017-19)). Driving patterns are adopted from Scottish and English travel surveys which show the length and the frequency of the trips. The daily trips for regular cars (excluding fleets and medium and heavy duty vehicles), are mostly less than 40 miles and only $1.5-2 \%$ of the trips is more than 100 miles (presented in Table $\mathrm{V})$. However, the fact that EVs are often recharged when the battery drops around $40 \%$ SoC (see [29]) implies that the actual charging demand will be more than the expected. Travel surveys further provide information about the percentage of trips made in different months and days of each week. For instance, the percentage of trips are quite similar throughout the weekdays and represents $15 \%$ of the trips, while weekend trips drop to $12.5 \%$. It is further assumed that drivers who has access to home chargers use level 1 chargers, while drivers residing in flats use level 2 and fast chargers. This statistics is obtained from the UK Power Network's Charger Use Study [30].

The simulation results for a cold week in January (7-13) is presented in Figures 6 and 7. Figure 6 shows the hourly energy consumption for optimum EV ambient temperatures (21.5 Celsius) and the actual weather conditions. The results are in line with the driving patterns and most of the demand occurs during the weekdays. In Figure 7, the difference between the optimum weather and the actual weather is presented. It can be seen that nearly $450 \mathrm{MW}$ of extra generation is needed support EVs during cold weather.

It is noteworthy that the simulation does not include high milage fleets such as taxis, private hires, delivery vehicles

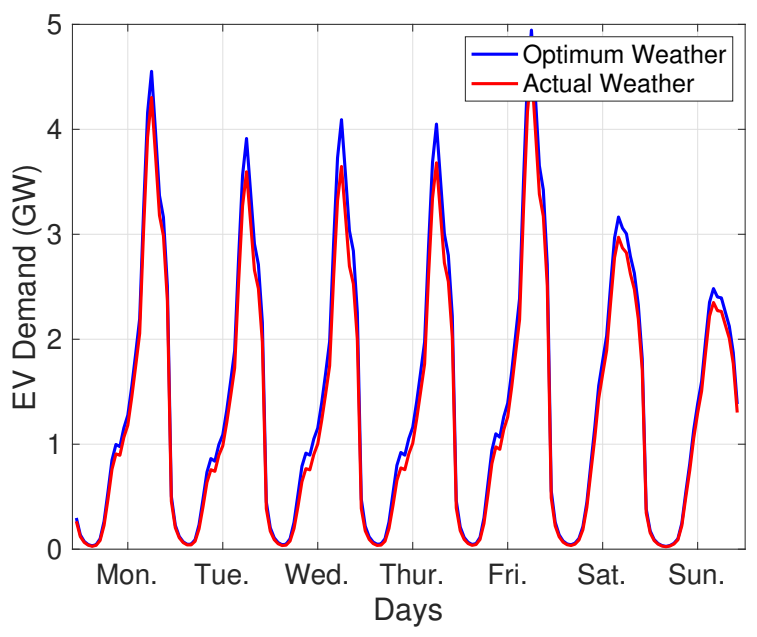

Fig. 6. Hourly demand for 11 million EVs for January 7-13.

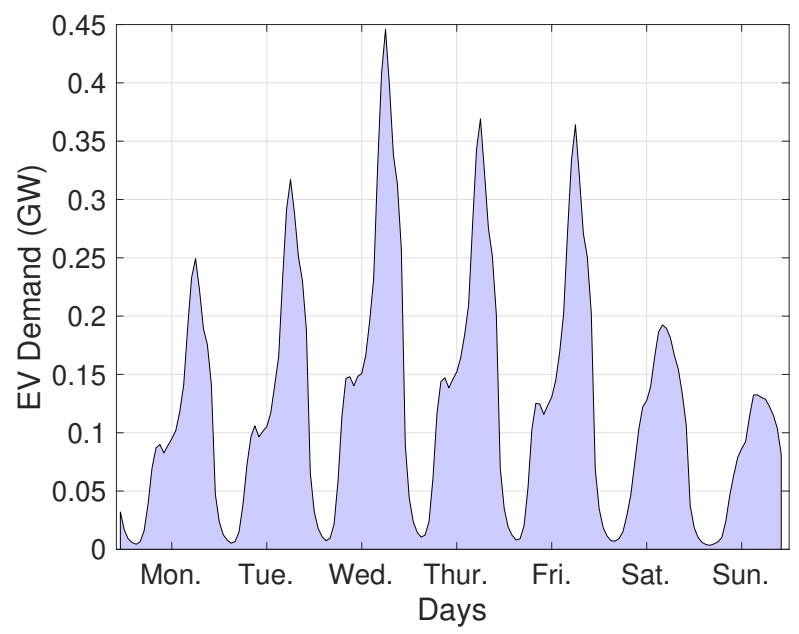

Fig. 7. Extra energy needed to drive in cold weather. Difference between optimum and actual temperature driving conditions for 11 million EVs in January 7-13.

and medium-duty vehicles. For instance, only in London area, there are more than $230 \mathrm{k}$ private hires and taxis are present. If the entire country is considered, such vehicles would represent an additional demand on the system. Moreover, in countries like United States, Canada, and Germany where daily driving ranges are higher than the UK, the impacts of cold weather charging would be significantly higher.

\section{CONClusions}

In this paper, we presented an overview of EV charging under cold weather and implications on EV battery, distribution network, and power generation. It was shown that cities with high EV penetration typically experience cold winter months, which requires the cold weather impacts to be investigated more carefully. The primary bottleneck in cold weather charging is the underlying lithium-ion battery which is required to be kept around $21.5^{\circ} \mathrm{C}$ to maximise its life cycle. 
TABLE VI

OVERVIEW OF DATASETS USED IN THE SIMULATION.

\begin{tabular}{llll}
\hline Parameter & Type & Probability Dist. & Notes \\
\hline No. of EVs and types & Deterministic & N/A & 11 million by 2030. Vehicle types from Table II. \\
Ambient Temperature & Probabilistic & Normal dist. & Based on historic data set \\
Driving Patterns & Probabilistic & Normal dist. & Based on travel surveys (Refs. [26] and [27]). \\
Start time of trips & Probabilistic & Empirical (discrete) dist. & Based on travel surveys \\
Length of trips & Probabilistic & Empirical (discrete) dist. & Probabilities based on travel surveys (Refs. [26] and [27]). \\
Weather Impacts & Deterministic & N/A & Based on empirical data Figure 1. \\
Initial-Final Battery State of Charge & Probabilistic & N/A & $40 \%$ to 80\%. \\
\hline
\end{tabular}

Therefore, with empirical data, it was shown that nearly 35$40 \% \mathrm{EV}$ range is reduced for heating purposes.

The impacts of cold weather charging on the power grid are summarised under two areas. First, fast charging of EVs will increase system harmonics. Therefore, it is important to estimate the number of EVs that can be simultaneously charged for different weather conditions. Second, there would be a need for more electrical energy as certain percentage of vehicles need to recharge more often. With simulation study, it was shown that there would be an additional need for $450 \mathrm{MW}$ generation for 11 million EVs in a typical 2030 penetration scenario.

\section{REFERENCES}

[1] İ. Batur, I. S. Bayram, and M. Koc, "Impact assessment of supply-side and demand-side policies on energy consumption and co2 emissions from urban passenger transportation: The case of istanbul," Journal of Cleaner Production, vol. 219, pp. 391-410, 2019.

[2] S. Pye, F. G. Li, J. Price, and B. Fais, "Achieving net-zero emissions through the reframing of uk national targets in the post-paris agreement era," Nature Energy, vol. 2, no. 3, pp. 1-7, 2017.

[3] B. K. Sovacool, L. Noel, J. Kester, and G. Z. de Rubens, "Reviewing nordic transport challenges and climate policy priorities: Expert perceptions of decarbonisation in denmark, finland, iceland, norway, sweden," Energy, vol. 165, pp. 532-542, 2018.

[4] N. Rietmann, B. Hügler, and T. Lieven, "Forecasting the trajectory of electric vehicle sales and the consequences for worldwide co2 emissions," Journal of Cleaner Production, vol. 261, p. 121038, 2020.

[5] I. S. Bayram, M. Devetsikiotis, and R. Jovanovic, "Optimal design of electric vehicle charging stations for commercial premises," International Journal of Energy Research, vol. n/a, no. n/a.

[6] "Electric vehicle strategy, scottish and souther electricity networks." [Online]. Available: http://news.ssen.co.uk/news/allarticles/2020/march/ssen-publishes-electric-vehicle-strategy-withcustomers-and-stakeholders-at-its-heart/

[7] C. d. M. Affonso and M. Kezunovic, "Probabilisitic sizing of pv generation on commercial parking lot with pevs to avoid transformer aging," in 2019 IEEE Milan PowerTech, June 2019, pp. 1-6.

[8] K. Clement-Nyns, E. Haesen, and J. Driesen, "The impact of charging plug-in hybrid electric vehicles on a residential distribution grid," IEEE Transactions on power systems, vol. 25, no. 1, pp. 371-380, 2009.

[9] M. Muratori, "Impact of uncoordinated plug-in electric vehicle charging on residential power demand," Nature Energy, vol. 3, no. 3, pp. 193201, 2018.

[10] R. Gold, "California wants cars to run on electricity. it's going to need a much bigger grid," September 2020, accessed: October 2020. [Online]. Available: https://www.wsj.com/articles/california-wants-cars-torun-on-electricity-its-going-to-need-a-much-bigger-grid-11601036583

[11] D. Luca de Tena and T. Pregger, "Impact of electric vehicles on a future renewable energy-based power system in europe with a focus on germany," International Journal of Energy Research, vol. 42, no. 8, pp. 2670-2685, 2018.

[12] C. F. Heuberger, P. K. Bains, and N. Mac Dowell, "The ev-olution of the power system: A spatio-temporal optimisation model to investigate the impact of electric vehicle deployment," Applied Energy, vol. 257, p. $113715,2020$.
[13] D. Ramsey, A. Bouscayrol, L. Boulon, and A. Vaudrey, "Simulation of an electric vehicle to study the impact of cabin heating on the driving range," in 2020 IEEE 91 st Vehicular Technology Conference (VTC2020Spring). IEEE, 2020, pp. 1-5.

[14] J. R. M. D. Reyes, R. V. Parsons, and R. Hoemsen, "Winter happens: The effect of ambient temperature on the travel range of electric vehicles," IEEE Transactions on Vehicular Technology, vol. 65, no. 6 , pp. 4016-4022, 2016.

[15] Y. Motoaki, W. Yi, and S. Salisbury, "Empirical analysis of electric vehicle fast charging under cold temperatures," Energy Policy, vol. 122, pp. 162-168, 2018.

[16] C. Vidal, O. Gross, R. Gu, P. Kollmeyer, and A. Emadi, "xev liion battery low-temperature effects," IEEE transactions on vehicular technology, vol. 68, no. 5, pp. 4560-4572, 2019.

[17] X.-G. Yang, T. Liu, and C.-Y. Wang, "Thermally modulated lithium iron phosphate batteries for mass-market electric vehicles," Nature Energy, vol. 6, no. 2, pp. 176-185, 2021.

[18] "Understand how temperature affects how far your ev can go on a full battery." [Online]. Available: https://www.geotab.com/fleetmanagement-solutions/ev-temperature-tool/

[19] J. Zhang, Z. Wang, P. Liu, and Z. Zhang, "Energy consumption analysis and prediction of electric vehicles based on real-world driving data," Applied Energy, vol. 275, p. 115408, 2020.

[20] E. Figenbaum, "Battery electric vehicle fast charging-evidence from the norwegian market," World Electric Vehicle Journal, vol. 11, no. 2, p. 38, 2020.

[21] G. Trentadue, A. Lucas, M. Otura, K. Pliakostathis, M. Zanni, and H. Scholz, "Evaluation of fast charging efficiency under extreme temperatures," Energies, vol. 11, no. 8, p. 1937, 2018.

[22] "Vehicle charging system testing, idaho national laboratory." [Online]. Available: https://avt.inl.gov/project-type/data

[23] "Vehicle charging system testing, idaho national laboratory." [Online]. Available: https://avt.inl.gov/evse-button/abb

[24] "Electromagnetic compatibility (emc) - part 3-2: Limits limits for harmonic current emissions." [Online]. Available: https://webstore.iec.ch/publication/63492

[25] R. Pogaki, "Western power distribution electric vehicle charging (pse0564001)," Tech. Rep., 2018.

[26] "National travel survey 2019." [Online]. Available: https://www.gov.uk/government/statistics/national-travel-survey-2019

[27] "Scottish transport statistics 2019." [Online]. Available: www.transport.gov.scot/publication/scottish-transport-statistics-no38-2019-edition/

[28] "Centre for environmental data analysis (ceda)." [Online]. Available: https://archive.ceda.ac.uk/

[29] M. Neaimeh, R. Wardle, A. M. Jenkins, J. Yi, G. Hill, P. F. Lyons, Y. Hübner, P. T. Blythe, and P. C. Taylor, "A probabilistic approach to combining smart meter and electric vehicle charging data to investigate distribution network impacts," Applied Energy, vol. 157, pp. 688-698, 2015.

[30] "Charger use study: Recharge the future." [Online]. Available: http://www.element-energy.co.uk/ 